\title{
The effect of renal function change on renal cell carcinoma patients with tumor thrombus after nephrectomy and thrombectomy: a large Chinese center experience
}

\author{
Zhuo Liư ${ }^{\dagger}$ Shiying Tang ${ }^{\dagger}$, Xiaojun Tian ${ }^{\dagger}$, Hongxian Zhang, Guoliang Wang, Shudong Zhang and Lulin Ma*
}

\begin{abstract}
Background: To explore the influencing factors of perioperative renal function change and their relationship with prognosis on renal cell carcinoma (RCC) patients with tumor thrombus after nephrectomy and thrombectomy.

Methods: The clinical and pathological data of 135 patients with RCC and tumor thrombus, who underwent nephrectomy and thrombectomy at Peking University Third Hospital from May 2015 to July 2018, was retrospectively analyzed. Absolute change in estimated glomerular filtration rate (eGFR) (ACE) and percent change in eGFR (PCE) were calculated by preoperative and postoperative renal function. Linear regression analysis was used to explore the influencing factors of ACE and PCE, and logistic regression analysis was used to explore the influencing factors of worse postoperative renal function [eGFR $660 \mathrm{~mL} /(\min \times 1.73 \mathrm{~m} \wedge 2)$ ]. Cancer-specific survival (CSS) was estimated by KaplanMeier method and multivariate Cox regression, which were used to explore the effect of ACE and PCE on prognosis.

Results: Of all the 135 patients, 101 patients (74.8\%) were male and 34 patients (25.2\%) were female. The mean preoperative eGFR was $73.9 \pm 21.8 \mathrm{~mL} /(\min \times 1.73 \mathrm{~m} \wedge 2)$ and postoperative eGFR was $69.5 \pm 25.2 \mathrm{~mL} /(\mathrm{min} \times 1.73 \mathrm{~m} \wedge 2)$. In multivariate linear regression analysis, preoperative eGFR $(P<0.001)$ and pathological type $(P=0.038)$ were significant predictive factors of ACE. In aspect of PCE, preoperative eGFR $(P<0.001)$ and pathological type $(P=0.002)$ were significant predictors. In multivariate logistic regression analysis, preoperative eGFR $(P=0.016)$ was the only risk factor of predicting worse postoperative renal function. During follow-up, 22 patients (16.3\%) were dead due to RCC. According to ROC analysis, the cut off value of ACE and PCE was 13.9 and 0.16, respectively. ACE $>13.9$ and PCE $>0.16$ indicated worse CSS $(P=0.006$ and $P=0.047$, respectively). However, in multivariate Cox regression analysis of several related factors, perinephric tissues invasion $(P=0.001)$, sarcomatoid differentiation $(P=0.001)$ and $A C E>13.9(P=0.002)$ were significant prognostic factors for CSS. PCE $>0.16$ seemed to be not $(P=0.055)$.

Conclusion: We explored several clinicopathological risk factors of predicting renal function change and their relationship with prognosis of RCC patients with tumor thrombus after nephrectomy and thrombectomy. The renal function change, which was associated with preoperative eGFR and pathological type, was prognostic risk factor for CSS and ACE> 13.9 indicated the worse prognosis.
\end{abstract}

Keywords: Renal cell carcinoma with tumor thrombus, Postoperative renal function, Absolute change in renal function, Percent change in renal function

\footnotetext{
* Correspondence: malulinpku@163.com

${ }^{\dagger}$ Zhuo Liu, Shiying Tang and Xiaojun Tian contributed equally to this work. Department of Urology, Peking University Third Hospital, 49 North Garden Rd., Haidian District, Beijing, People's Republic of China
}

(c) The Author(s). 2020 Open Access This article is distributed under the terms of the Creative Commons Attribution 4.0 International License (http://creativecommons.org/licenses/by/4.0/), which permits unrestricted use, distribution, and reproduction in any medium, provided you give appropriate credit to the original author(s) and the source, provide a link to the Creative Commons license, and indicate if changes were made. The Creative Commons Public Domain Dedication waiver (http://creativecommons.org/publicdomain/zero/1.0/) applies to the data made available in this article, unless otherwise stated. 


\section{Background}

Renal cell carcinoma (RCC) represents $2-3 \%$ of all cancers [1], and this data was $2.2 \%$ in China [2]. The incidence of RCC has increased approximately $5 \%$ of new cancers in the USA [3] and ascended about 2\% steadily in European union over the past decade [4]. Moreover, of all the patients with RCC, approximate $4-10 \%$ have vein invasion, including the renal vein or/and the inferior vena cava (IVC) which could even extend up to the right atrium [1]. For these patients, radical nephrectomy (RN) with thrombectomy appears to be the gold standard of treatment gradually, which offers the potential cure with a 5year cancer-specific survival (CSS) of 40-65\% [1]. Furthermore, patients following cytoreductive nephrectomy $(\mathrm{CN})$ have a longer overall survival (OS) compared with those without $\mathrm{CN}$ (23.9 vs. 9 months, $P<0.001$ ) [5].

Although there are several effective treatments for this malignant tumor, patients are still at a certain risk of reduction in renal function due to loss of renal tissue after performing RN with thrombectomy [6]. Zabor et al. [6] explored the long-term renal function recovery after RN and demonstrated that only $45 \%$ of patients had renal function recovery in 2 years. Several models have been made to predict the probability of renal function recovery in patients following pure RN [7, 8]. 2017 AUA guidelines also recommended that it was necessary for clinicians to consider renal function outcomes when making management process [9]. In previous multicenter studies of RCC patients after RN, old age, low preoperative estimated glomerular filtration rate (eGFR) and high comorbidity are the significant predictive factors of poor postoperative renal function [10-12].

However, to our knowledge, there was less research about evaluating the effect of perioperative renal function change in RCC patients with tumor thrombus (TT). Thus, while trying to validate the previous conclusion in pure $\mathrm{RN}$, our aim is to explore the influencing factors of perioperative renal function change and their relationship with prognosis on RCC patients with TT after nephrectomy and thrombectomy in a large Chinese center.

\section{Methods}

From May 2015 to July 2018, 135 patients with RCC with TT who underwent $\mathrm{RN}$ or $\mathrm{CN}$ and thrombectomy at Peking University Third Hospital was retrospectively analyzed. All the patients underwent routine blood examinations, chest and abdominal computed tomography (CT) or magnetic resonance imaging (MRI), and/or bone scans preoperatively. Before surgery, a multidisciplinary team, including specialists from urology, general surgery, cardiac surgery, anesthesiology, and radiology departments, gives a comprehensive assessment of the patient.

Demographic and clinicopathological data were evaluated. The level of TT was classified according to the Mayo classification [13]. Renal function was assessed by eGFR, which was based on serum creatinine calculated by the Modification of Diet in Renal Disease (MDRD) [14] in one week preoperatively and 1 month postoperatively. The change of perioperative renal function was presented by absolute change in eGFR (ACE) and percent change in eGFR (PCE), which were proposed by Haifler et al. ACE = eGFRpostoperative - $\mathrm{eGFR}$ preoperative and $\mathrm{PCE}=(\mathrm{eGFR}$ postoperative -

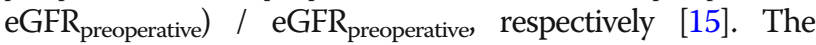
American Society of Anesthesiologists classification was used to classify physical condition and surgical risk [16]. The postoperative complications were evaluated by modified Clavien grading system [17] and grade higher than III was considered to be a serious complication. The postoperative specimens were evaluated by two experienced pathologists in our institution. Pathological features including histology and tumor grade were also reviewed according to the 2016 World Health Organization (WHO) classification [18].

Cytoreductive nephrectomy refers to the patients with possible metastasis found by imaging before operation. For the metastasis renal cell carcinoma and tumor thrombus patients with good condition who can tolerate operation, we also suggest them operation treatment. Because the growth rate of tumor thrombus usually grows faster, which may cause sudden cardiac death caused by atrial cancer thrombus. Appropriate treatments, such as immunotherapy and targeted therapy, were provided in cases of local recurrence or distant metastasis in our study. Follow-up, including laboratory data, chest radiography, urinary ultrasonography, and enhanced urinary CT/MRI, was performed every 3 months in the first year, every 6 months until year 5 , and annually thereafter. The co-primary endpoints of the study were cancer-specific death, and all-cause mortality.

Continuous variables were presented as the mean value $\pm \mathrm{SD}$ and were analyzed using Mann-Whitney $\mathrm{U}$ test. Categorical variables were compared by using the Pearson $x^{2}$ test. Linear regression analysis was used to explore the risk factors of $\mathrm{ACE}$ and $\mathrm{PCE}$, and logistic regression analysis was used to explore the predictors of postoperative renal insufficiency $\left[\mathrm{eGFR} \leq 60 \mathrm{~mL} /\left(\mathrm{min} \times 1.73 \mathrm{~m}^{\wedge} 2\right)\right]$. We made multivariate analysis for factors which had statistical significance in univariate analysis. The significant factors of univariate analysis were CSS was estimated by the KaplanMeier method and compared by log-rank test in different level of ACE and PCE, which was calculated by Receiver Operating Characteristic (ROC) curve. A two-sided $P$ value $<0.05$ was considered to be statistically significant. All data were collected and analyzed by SPSS 22.0 software (IBM Corp, Armonk, NY, USA).

\section{Results}

Demographic and clinicopathological characteristics of 135 patients with RCC with TT, including 101 (74.8\%) 
males and 34 (25.2\%) females, are summarized in Table 1. The mean of preoperative eGFR was $73.9 \pm 21.8 \mathrm{~mL} /$ $\left(\min \times 1.73 \mathrm{~m}^{\wedge} 2\right)$ and postoperative eGFR was $69.5 \pm$ $25.2 \mathrm{~mL} /\left(\min \times 1.73 \mathrm{~m}^{\wedge} 2\right)$. The postoperative eGFR of 42 patients $(31.1 \%)$ was below $60 \mathrm{~mL} /\left(\mathrm{min} \times 1.73 \mathrm{~m}^{\wedge} 2\right)$ and 93 patients $(68.9 \%)$ had adequate renal function [> $\left.60 \mathrm{~mL} /\left(\mathrm{min} \times 1.73 \mathrm{~m}^{\wedge} 2\right)\right]$. There were $31(23.0 \%)$ patients with renal vein tumor thrombus and 104 (77.0\%) with IVC tumor thrombus including 38 with level I, 39 with level II, 16 with level III and 11 with level IV.

All the patients underwent $\mathrm{RN}$ or $\mathrm{CN}$ with thrombectomy successfully. There are four patients with thoracotomy and extracorporeal circulation; two patients with thoracotomy without extracorporeal circulation; others without thoracotomy. During operation, It is common to clam the contralateral renal vein. Only one patients underwent venal graft placement. During the operation, the distal end of inferior vena cava was found to be free of tumor invasion. A part of the uninjured wall of inferior vena cava was resected and reconstructed as the distal end of renal vein in the healthy side to ensure renal blood flow in the healthy side.

For operation-related data, the mean operation time was $337.0 \pm 122.7 \mathrm{~min}$ and the mean intraoperative blood loss $1387.7 \pm 1640.6 \mathrm{ml}$. Fifty six patients had postoperative complications according to Clavien classification, while only 18 patients had serious complications. In all patients, 115 patients had clear cell carcinoma and 20 patients were other histological types. The median follow-up was 11.4 months (range: 0-37). During follow-up, 22 patients (16.3\%) were dead due to the disease. The 1-year CSS of patients with low preoperative renal function is $87.5 \%$ and 2 -year CSS of these is $58.3 \%$. The 1 -year CSS of patients with low postoperative renal function is $84.9 \%$ and 2 -year CSS of these is $79.2 \%$. The 3 -year CSS of all the patients is $91.5 \%$ and 5 -year CSS of these is $86.0 \%$.

In multivariate linear regression analysis, preoperative eGFR $(P<0.001)$ and pathological type $(P=0.038)$ were significant predictive factors of ACE (Table 2). In aspect of PCE, preoperative eGFR $(\mathrm{P}<0.001)$ and pathological type $(P=0.002)$ were significant predictors (Table 3$)$. In multivariate logistic regression analysis, preoperative eGFR $(P=0.016)$, was the only risk factor of predicting worse postoperative renal function defined as eGFR $\leq 60$ $\mathrm{mL} /\left(\mathrm{min} \times 1.73 \mathrm{~m}^{\wedge} 2\right)$ (Table 4$)$. According to ROC curve analysis, the cut off value of ACE and PCE was 13.9 and 0.16 , respectively. $\mathrm{ACE}>13.9$ and $\mathrm{PCE}>0.16$ indicated worse CSS $(P=0.006$ and $P=0.047$, respectively) in Kaplan-Meier analysis (Fig. 1a \& b). However, in multivariate Cox regression analysis of several related factors, perinephric tissues invasion $(P=0.001)$, sarcomatoid differentiation $(\mathrm{P}=0.001)$ and $\mathrm{ACE}>13.9(P=0.002)$ were significant prognostic factors for CSS. PCE $>0.16$ seemed to be not $(P=0.055)$ (Table 5$)$.

\section{Discussion}

In RCC patients with TT, RN with thrombectomy combined with metachronous adjuvant therapy seems to be the most effective methods to better prognosis [1]. However, this surgical methods might have effect on renal function owing to the loss of renal tissue and targeted therapy also has a certain impact on serum creatinine in patients with advanced RCC [19]. In previous studies, several researches have been conducted to confirm the risk factors of postoperative renal function following pure $\mathrm{RN}[6,20,21]$, while the conclusions were still in controversy and lack of data of which after thrombectomy. Thus, in order to validate and consummate previous results, we selected these specified patients and explored the effect of renal function change after nephrectomy and thrombectomy in a large Chinese center.

In our study, we validated the serum creatinine increased and the eGFR decreased postoperatively, revealing that $\mathrm{RN}$ with thrombectomy might also have an effect on patients' renal function which was associated with $\mathrm{OS}^{22}$. Moreover, we made multivariate logistic regression analysis and showed that preoperative eGFR was the only risk factors of predicting chronic kidney disease $\left[\mathrm{eGFR} \leq 60 \mathrm{~mL} /\left(\mathrm{min} \times 1.73 \mathrm{~m}^{\wedge} 2\right)\right]$. In addition, the ACE and PCE were also vital important variables in evaluating renal function [15]. The greater the change of eGFR, the more apparent the descending of renal function after operation. It was also showed that among all the significant predictive factors, only the preoperative eGFR and non-clear cell carcinoma correlated with the postoperative decreased renal function assessed by both ACE and PCE. The renal dysfunction also had influence in patients' prognosis and we discovered that a cutoff value of 13.9 in $\mathrm{ACE}$ and 0.16 in PCE indicated a poor CSS respectively.

After following RN, the renal function of RCC patients significantly declined [22]. Yokoyama et al. [23] reviewed 341 Asian patients with RCC and found that the 3-year probability of $\mathrm{eGFR}>60 \mathrm{~mL} /\left(\min \times 1.73 \mathrm{~m}^{\wedge} 2\right)$ was $63 \%$, while up to $11 \%$ patients suffered renal dysfunction of $\mathrm{eGFR} \leq 45 \mathrm{~mL} /\left(\min \times 1.73 \mathrm{~m}^{\wedge} 2\right)$. Similarly, in another retrospective cohort study [24], the proportion was 65 and $36 \%$ respectively. In short-term renal function assessment, Tanaka et al. [25] demonstrated a 37\% decreased in renal function of 155 patients in the following 2-4 weeks after RN. In one year after RN, the eGFR decreased by $27-36 \%[23,26,27]$. In the present study, we observed a mean increase of $17.2 \%$ in serum creatinine and the chronic kidney disease (CKD) patients increased by $18.5 \%$ after $\mathrm{RN}$ with thrombectomy (29 vs. $42 \mathrm{CKD}$ patients). What's more, our finding in $\mathrm{RN}$ with thrombectomy was compatible with previous studies of pure $\mathrm{RN}$, which results accorded with our sense. Table 2 and Table 3 further demonstrated that different TT levels 
Table 1 Patient demographic and postoperative data

\begin{tabular}{ll}
\hline Paprameters & $\mathrm{n} / \mathrm{x} \pm \mathrm{s}$ \\
\hline Gender & \\
Male & 101 \\
Female & 34 \\
Age, years & $59.2 \pm 10.8$ \\
Body mass index, $\mathrm{kg} / \mathrm{m} \wedge 2$ & $23.5 \pm 3.6$
\end{tabular}

ASA classification

1

2

3

Side

Left

Tumor diameter, cm

Tumor thrombus grade

O
I
II
II
IV

Preoperative serum creatinine, $\mu \mathrm{mol} / \mathrm{L}$

Postoperative serum creatinine, $\mu \mathrm{mol} / \mathrm{L}$

Preoperative eGFR, $\mathrm{mL} /(\min \times 1.73 \mathrm{~m} \wedge 2)$

Postoperative eGFR, $\mathrm{mL} /(\min \times 1.73 \mathrm{~m} \wedge 2)$

Operation approach

Laparoscopic approach

Open approach

Ipsilateral adrenalectomy

No

Yes

T stage

T3a

$\mathrm{T} 3 \mathrm{~b}$

$\mathrm{T} 3 \mathrm{C}$

$\mathrm{T} 4$

Lymph node dissection

No

Yes

Vascular wall invasion

No

Yes

Operation time, min

Intraoperative hemorrhage, $\mathrm{ml}$

Pathological type

Clear cell carcinoma
Table 1 Patient demographic and postoperative data (Continued)

\begin{tabular}{|c|c|}
\hline Paprameters & $n / x \pm s$ \\
\hline Non clear cell carcinoma & 20 \\
\hline \multicolumn{2}{|c|}{ WHO/ISUP 2016 Nuclear classification } \\
\hline 1 & 3 \\
\hline 2 & 47 \\
\hline 3 & 51 \\
\hline 4 & 34 \\
\hline \multicolumn{2}{|l|}{ Lymph node metastasis } \\
\hline No & 125 \\
\hline Yes & 10 \\
\hline \multicolumn{2}{|c|}{ Metastasis or invasion of adrenal glands } \\
\hline No & 117 \\
\hline Yes & 18 \\
\hline \multicolumn{2}{|l|}{ Metastasis } \\
\hline No & 100 \\
\hline Yes & 35 \\
\hline \multicolumn{2}{|l|}{ Lymphatic vascular invasion } \\
\hline No & 106 \\
\hline Yes & 29 \\
\hline \multicolumn{2}{|l|}{ Perinephric tissues invasion } \\
\hline No & 94 \\
\hline Yes & 41 \\
\hline \multicolumn{2}{|l|}{ Renal pelvis invasion } \\
\hline No & 105 \\
\hline Yes & 30 \\
\hline \multicolumn{2}{|l|}{ Necrosis } \\
\hline No & 66 \\
\hline Yes & 69 \\
\hline \multicolumn{2}{|l|}{ Sarcomatoid differentiation } \\
\hline No & 113 \\
\hline Yes & 22 \\
\hline \multicolumn{2}{|l|}{ Postoperative complications } \\
\hline No & 79 \\
\hline Yes & 56 \\
\hline \multicolumn{2}{|l|}{ Serious complications } \\
\hline No & 38 \\
\hline Yes & 18 \\
\hline
\end{tabular}

eGFR estimated glomerular filtration rate, ISUP International Society of Urological Pathology, ASA American Society of Anesthesiologists

were not associated with renal function change, which preliminary proved the irrelevance between TT and renal function. In the future, a cohort study of the comparison of postoperative renal function with and without TT needs to be made to further clarify this conclusion. Our study showed these data of perioperative renal 
Table 2 Linear regression analysis of absolute change in eGFR

\begin{tabular}{|c|c|c|c|c|c|c|}
\hline \multirow[t]{2}{*}{ Variables } & \multicolumn{3}{|c|}{ Univariate analysis } & \multicolumn{3}{|c|}{ Multivariate analysis } \\
\hline & $\bar{B}$ & $95 \% \mathrm{Cl}$ & $P$ & $\bar{B}$ & $95 \% \mathrm{Cl}$ & $P$ \\
\hline Gender (female vs. male) & 5.724 & $-3.977-15.426$ & 0.245 & & & \\
\hline Age & -0.208 & $-0.599-0.183$ & 0.295 & & & \\
\hline Body mass index & 0.105 & $-1.090-1.301$ & 0.862 & & & \\
\hline ASA classification & -6.273 & $-15.458-2.912$ & 0.179 & & & \\
\hline Side (right vs. left) & 1.175 & $-7.626-9.975$ & 0.792 & & & \\
\hline Tumor diameter & 0.975 & $-0.228-2.178$ & 0.111 & & & \\
\hline Tumor thrombus grade & 0.521 & $-3.013-4.055$ & 0.771 & & & \\
\hline Preoperative serum creatinine & 0.079 & $0.027-0.132$ & $0.003^{*}$ & - & - & - \\
\hline Preoperative eGFR & -0.476 & $-0.653--0.299$ & $<0.001^{*}$ & -0.455 & $-0.631--0.278$ & $<0.001$ \\
\hline Operation approach (open vs. laparoscopy) & 2.11 & $-6.387-10.607$ & 0.624 & & & \\
\hline Operation time & 0.022 & $-0.013-0.056$ & 0.213 & & & \\
\hline Pathological type (non-clear cell carcinoma vs. clear cell carcinoma) & 14.612 & $2.964-26.260$ & $0.014^{*}$ & 11.416 & $0.658-22.174$ & $0.038^{*}$ \\
\hline Vascular wall invasion (present vs. absent) & 6.462 & $-2.135-15.058$ & 0.139 & & & \\
\hline Lymphatic vascular invasion (present vs. absent) & -4.479 & $-14.733-5.775$ & 0.389 & & & \\
\hline Perinephric tissues invasion (present vs. absent) & -2.692 & $-11.876-6.491$ & 0.563 & & & \\
\hline Renal pelvis invasion (present vs. absent) & 7.211 & $-2.872-17.293$ & 0.16 & & & \\
\hline Necrosis (present vs. absent) & -1.846 & $-10.338-6.646$ & 0.668 & & & \\
\hline Sarcomatoid differentiation (present vs. absent) & -1.769 & $-13.193-9.655$ & 0.76 & & & \\
\hline
\end{tabular}

eGFR estimated glomerular filtration rate, ISUP International Society of Urological Pathology; ${ }^{*} p<0.05$

Table 3 Linear regression analysis of percent change in eGFR

\begin{tabular}{|c|c|c|c|c|c|c|}
\hline \multirow[t]{2}{*}{ Variables } & \multicolumn{3}{|c|}{ Univariate analysis } & \multicolumn{3}{|c|}{ Multivariate analysis } \\
\hline & $B$ & $95 \% \mathrm{Cl}$ & $P$ & $\mathrm{~B}$ & $95 \% \mathrm{Cl}$ & $P$ \\
\hline Gender (female vs. male) & 0.047 & $-0.289-0.383$ & 0.782 & & & \\
\hline Age & -0.009 & $-0.023-0.004$ & 0.182 & & & \\
\hline Body mass index & 0.028 & $-0.013-0.069$ & 0.182 & & & \\
\hline ASA classification & -0.107 & $-0.426-0.212$ & 0.507 & & & \\
\hline Side (right vs. left) & -0.167 & $-0.469-0.135$ & 0.276 & & & \\
\hline Tumor diameter & 0.044 & $0.003-0.085$ & $0.037^{*}$ & 0.037 & $-0.001-0.074$ & 0.058 \\
\hline Tumor thrombus grade & 0.016 & $-0.106-0.138$ & 0.794 & & & \\
\hline Preoperative serum creatinine & 0.01 & $0.009-0.011$ & $<0.001^{*}$ & - & - & - \\
\hline Preoperative eGFR & -0.014 & $-0.020--0.007$ & $<0.001^{*}$ & -0.013 & $-0.019--0.007$ & $<0.001$ \\
\hline Operation approach (open vs. laparoscopy) & -0.101 & $-0.394-0.192$ & 0.496 & & & \\
\hline Operation time & 0.001 & $0.000-0.002$ & 0.094 & & & \\
\hline Pathological type (non-clear cell carcinoma vs. clear cell carcinoma) & 0.59 & $0.191-0.988$ & $0.004^{*}$ & 0.623 & $0.236-1.010$ & $0.002^{*}$ \\
\hline Vascular wall invasion (present vs. absent) & 0.247 & $-0.049-0.543$ & 0.101 & & & \\
\hline Lymphatic vascular invasion (present vs. absent) & -0.128 & $-0.485-0.229$ & 0.48 & & & \\
\hline Perinephric tissues invasion (present vs. absent) & 0.156 & $-0.163-0.475$ & 0.336 & & & \\
\hline Renal pelvis invasion (present vs. absent) & 0.368 & $0.020-0.716$ & $0.038^{*}$ & & & \\
\hline Necrosis (present vs. absent) & -0.16 & $-0.455-0.134$ & 0.284 & & & \\
\hline Sarcomatoid differentiation (present vs. absent) & -0.066 & $-0.464-0.332$ & 0.743 & & & \\
\hline
\end{tabular}


Table 4 Univariate and multivariate Logistic regression analysis of clinical data and worse postoperative renal function [eGFR $\leq 60$ $\left.\mathrm{mL} /\left(\min \times 1.73 \mathrm{~m}^{\wedge} 2\right)\right]$

\begin{tabular}{|c|c|c|c|c|c|c|}
\hline \multirow[t]{2}{*}{ Variables } & \multicolumn{3}{|c|}{ Univariate analysis } & \multicolumn{3}{|c|}{ Multivariate analysis } \\
\hline & $\overline{\mathrm{OR}}$ & $95 \% \mathrm{Cl}$ & $P$ & $\overline{\mathrm{OR}}$ & $95 \% \mathrm{Cl}$ & $P$ \\
\hline Gender (female vs. male) & 1.108 & $0.390-3.147$ & 0.847 & & & \\
\hline Age & 1 & $0.962-1.040$ & 0.999 & & & \\
\hline Body mass index & 0.905 & $0.804-1.020$ & 0.101 & & & \\
\hline \multicolumn{7}{|l|}{ ASA classification } \\
\hline 1 & - & - & 0.437 & & & \\
\hline$\|$ & 0.25 & $0.030-2.081$ & 0.2 & & & \\
\hline III & 0.25 & $0.026-2.416$ & 0.231 & & & \\
\hline Side (right vs. left) & 0.817 & $0.325-2.050$ & 0.666 & & & \\
\hline Tumor diameter & 1.088 & $0.944-1.254$ & 0.247 & & & \\
\hline \multicolumn{7}{|l|}{ Tumor thrombus grade } \\
\hline 0 & - & - & 0.232 & & & \\
\hline । & 0.24 & $0.058-0.991$ & $0.049^{*}$ & & & \\
\hline$\|$ & 0.216 & $0.052-0.898$ & $0.035^{*}$ & & & \\
\hline III & 0.54 & $0.077-3.775$ & 0.535 & & & \\
\hline IV & 0.42 & $0.058-3.029$ & 0.389 & & & \\
\hline Preoperative serum creatinine & 0.966 & $0.938-0.994$ & $0.019^{*}$ & - & - & - \\
\hline Preoperative eGFR & 1.054 & $1.013-1.096$ & $0.009^{*}$ & 1.049 & $1.009-1.092$ & $0.016^{*}$ \\
\hline Operation approach (open vs. laparoscopy) & 1.576 & $0.642-3.864$ & 0.321 & & & \\
\hline Ipsilateral adrenalectomy (present vs. absent) & 1.492 & $0.615-3.616$ & 0.376 & & & \\
\hline Lymph node dissection (present vs. absent) & 0.821 & $0.339-1.992$ & 0.663 & & & \\
\hline Operation time & 0.998 & $0.995-1.002$ & 0.344 & & & \\
\hline Pathological type (non-clear cell carcinoma vs. clear cell carcinoma) & 2.692 & $0.570-12.707$ & 0.211 & & & \\
\hline WHO/ISUP 2016 Nuclear classification (12vs. 34) & 2.277 & $0.937-5.534$ & 0.069 & & & \\
\hline Lymph node metastasis (present vs. absent) & 1.134 & $0.220-5.847$ & 0.881 & & & \\
\hline Metastasis (present vs. absent) & 2.897 & $0.789-10.627$ & 0.109 & & & \\
\hline Vascular wall invasion (present vs. absent) & 0.482 & $0.195-1.192$ & 0.114 & & & \\
\hline Lymphatic vascular invasion (present vs. absent) & 1.864 & $0.573-6.067$ & 0.301 & & & \\
\hline Perinephric tissues invasion (present vs. absent) & 0.776 & $0.302-1.991$ & 0.598 & & & \\
\hline Renal pelvis invasion (present vs. absent) & 1.152 & $0.378-3.505$ & 0.804 & & & \\
\hline Necrosis (present vs. absent) & 0.372 & $0.145-0.956$ & $0.04^{*}$ & 0.384 & $0.145-1.015$ & 0.054 \\
\hline Sarcomatoid differentiation (present vs. absent) & 0.718 & $0.244-2.114$ & 0.548 & & & \\
\hline Postoperative complications (present vs. absent) & 0.851 & $0.352-2.056$ & 0.72 & & & \\
\hline
\end{tabular}

eGFR estimated glomerular filtration rate, ISUP International Society of Urological Pathology, ASA American Society of Anesthesiologists; ${ }^{*} p<0.05$

function in order for clinicians to have a rough prediction preoperatively and make more active monitoring postoperatively.

After that, we also explore influencing factors of postoperative renal function, as well as its change rate. Preoperative eGFR seemed to be an important variable in assessing postoperative renal function, which was similar to previous studies. Lane et al. [28] reviewed 1169 patients with RN and concluded that low preoperative eGFR was associated with postoperative renal dysfunction. Krebs et al. [22] also suggested patients with preoperative poor renal function were at risk of postoperative end-stage kidney disease. This is well understood that postoperative renal function is related with preoperative one. What's more, we divided the pathological features into two parts: clear cell carcinoma and non-clear cell carcinoma. According to the 2016 WHO classification [18], non-clear cell carcinoma consists of papillary renal cell carcinoma, nephroblastoma and Xp11.2 translocations/TFE3 gene fusion in our study. Interestingly, the present study also showed that the type 

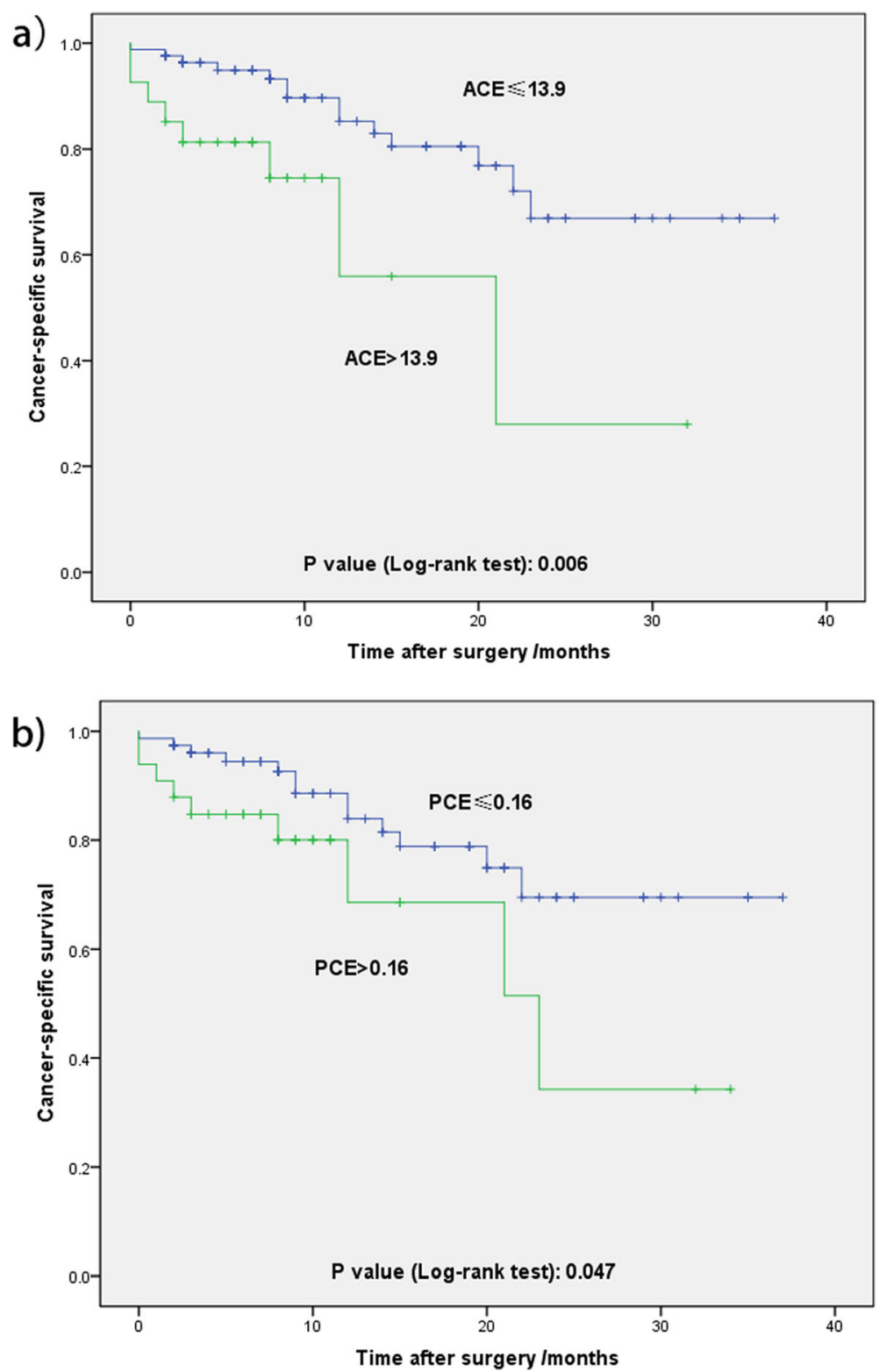

Fig. 1 a) Kaplan-Meier survival curves for cancer-specific survival for the cut-off value of ACE. b) Kaplan-Meier survival curves for cancer-specific survival for the cut-off value of PCE

of non-clear cell carcinoma was associated with greater renal function change, which indicated worse postoperative renal function. We assumed that different pathological types originated in specified histology, which might result in different effects on renal function. Mohammed et al. [29] found the histological types of RCCs arising in end-stage renal disease (ESRD) differed from that of sporadic RCCs. Moreover, Solomon et al. [30] studied a large cohort of RCC patients and found that declining renal function was independently related with an increased likelihood of papillary renal cell carcinoma histology, for the reason of protein expression with kidney injury. On the other hand, in Additional file 1: Table S1, we found the relationship between pathological histology and operation time, which was potentially associated with postoperative renal function. It was extremely hypothesized that for patients with normal preoperative renal function, the pathological type seemed more significant to indicate the decline of renal function postoperatively, considering that different biological characteristics, genetic mechanisms and clinicopathological variables in some aspect.

Several researches have been established to explore the prognostic outcomes after RN with thrombectomy. Tang et al. [31] carried on a median time of 45 months in follow- 
Table 5 Univariate and multivariate Cox regression analysis of CSS in patients with renal cell carcinoma and tumor thrombus after radical nephrectomy and thrombectomy

\begin{tabular}{|c|c|c|c|c|c|c|}
\hline \multirow[t]{2}{*}{ Variables } & \multicolumn{3}{|c|}{ Univariate analysis } & \multicolumn{3}{|c|}{ Multivariate analysis } \\
\hline & $\mathrm{OR}$ & $95 \% \mathrm{Cl}$ & $P$ & $\overline{\mathrm{OR}}$ & $95 \% \mathrm{Cl}$ & $P$ \\
\hline Gender (female vs. male) & 0.327 & $0.076-1.405$ & 0.133 & & & \\
\hline Age & 0.995 & $0.955-1.036$ & 0.808 & & & \\
\hline Body mass index & 0.974 & $0.867-1.093$ & 0.651 & & & \\
\hline \multicolumn{7}{|l|}{ ASA classification } \\
\hline 1 & - & - & 0.3 & & & \\
\hline$\|$ & 0.942 & $0.123-7.189$ & 0.954 & & & \\
\hline III & 1.996 & $0.238-16.772$ & 0.524 & & & \\
\hline Side (right vs. left) & 0.762 & $0.325-1.786$ & 0.532 & & & \\
\hline Tumor diameter & 1.088 & $0.978-1.210$ & 0.122 & & & \\
\hline Tumor thrombus grade & & & 0.944 & & & \\
\hline 0 & - & - & 0.716 & & & \\
\hline । & 0.474 & $0.138-1.621$ & 0.234 & & & \\
\hline$\|$ & 0.706 & $0.222-2.248$ & 0.556 & & & \\
\hline$\|$ & 1.172 & $0.342-4.012$ & 0.801 & & & \\
\hline IV & 0.732 & $0.152-3.527$ & 0.697 & & & \\
\hline Preoperative serum creatinine & 0.999 & $0.991-1.008$ & 0.885 & & & \\
\hline Preoperative eGFR & 1 & $0.979-1.020$ & 0.973 & & & \\
\hline Operation approach (open vs. laparoscopy) & 2.085 & $0.890-4.884$ & 0.091 & & & \\
\hline Ipsilateral adrenalectomy (present vs. absent) & 2.087 & $0.846-5.149$ & 0.11 & & & \\
\hline Lymph node dissection (present vs. absent) & 3.008 & $1.109-8.162$ & $0.031^{*}$ & & & \\
\hline Operation time & 1.002 & $0.999-1.005$ & 0.174 & & & \\
\hline Pathological type (non-clear cell carcinoma vs. clear cell carcinoma) & 1.996 & $0.767-5.037$ & 0.159 & & & \\
\hline WHO/ISUP 2016 Nuclear classification(12vs.34) & 3.843 & $1.135-13.012$ & $0.031^{*}$ & & & \\
\hline \multicolumn{7}{|l|}{ T stage } \\
\hline \multicolumn{7}{|l|}{ T3а } \\
\hline \multicolumn{7}{|l|}{ T3b } \\
\hline \multicolumn{7}{|l|}{ T3c } \\
\hline \multicolumn{7}{|l|}{ T4 } \\
\hline Lymph node metastasis (present vs. absent) & 4.166 & $1.522-11.402$ & $0.005^{*}$ & & & \\
\hline Metastasis (present vs. absent) & 2.04 & $0.870-4.782$ & 0.101 & & & \\
\hline Vascular wall invasion (present vs. absent) & 1.18 & $0.471-2.952$ & 0.724 & & & \\
\hline Lymphatic vascular invasion (present vs. absent) & 2.305 & $0.996-5.334$ & 0.051 & & & \\
\hline Perinephric tissues invasion (present vs. absent) & 4.029 & $1.709-9.497$ & $0.001^{*}$ & 4.497 & $1.844-10.970$ & $0.001^{*}$ \\
\hline Renal pelvis invasion (present vs. absent) & 1.876 & $0.679-5.180$ & 0.225 & & & \\
\hline Necrosis (present vs. absent) & 1.704 & $0.729-3.981$ & 0.219 & & & \\
\hline Sarcomatoid differentiation (present vs. absent) & 3.417 & $1.431-8.160$ & $0.006^{*}$ & 4.666 & $1.834-11.873$ & $0.001^{*}$ \\
\hline Postoperative complications (present vs. absent) & 2.499 & $1.016-6.146$ & $0.046^{*}$ & 2.243 & $0.898-5.603$ & 0.084 \\
\hline ACE (> 13.9 vs. $\leq 13.9)$ & 3.274 & $1.331-8.052$ & $0.01^{*}$ & 4.2 & $1.657-10.642$ & $0.002^{*}$ \\
\hline PCE (>0.16 vs. $\leq 0.16)$ & 2.322 & $0.982-5.494$ & 0.055 & & & \\
\hline
\end{tabular}


up and demonstrated that higher tumor thrombus level, lymph node and metastasis stages and adrenal gland invasion were the negative prognostic predictors significantly. However, previous studies did not include some useful index with renal function. Thus, we supplied previous studies and use ACE and PCE as predictive variables to make prognostic analysis, indicating that the $\mathrm{ACE}>13.9$ or PCE $>0.16$ was significant risk factor in CSS. ACE and PCE seemed to be more accurate index in evaluate perioperative renal function and renal dysfunction. These results counseled our urologists that these patients had shorter survival time and more active monitoring of renal function should be done.

In our single institution experience, the reason of renal insufficiency after RN with thrombectomy consists of at least two aspects. One is renal ischemia caused by uninjured renal vein occlusion during operation. The other might be caused by insufficient circulation volume due to a large amount of bleeding during operation. In addition, the urine color and volume should be closely observed after operation. Several serum markers, such as serum creatinine, urea and electrolyte, should also be monitored. For patients with oliguria, increased serum creatinine or urea, it is recommended to supply blood volume and perform diuretic therapy in time, even making blood dialysis therapy if necessary.

Limitations of the study include that this is a retrospective and single institution study. In addition, lymph node was independent prognostic factor in univariate analysis, but not in multivariate analysis, as well as metastasis. These results might be attributed to the small sample size of the patients in our group patients, for the reason that this is a disease with a relatively low incidence and the number of patients who can be operated on is much less. In addition, the renal function is truly influenced by many factors. Our article only lists some of them, which is not comprehensive enough. However, there seems to be less studies about renal function changes in TT patients in our knowledge and our study has obtained some conclusions for foundation of further research. Therefore, next research needs lager cohort, more multi-center and prospective studies and we expect a new more complex index including all prognostic predictors in assessing the change of perioperative renal function of patients following RN with thrombectomy in the future.

\section{Conclusions}

We explored several clinicopathological risk factors of predicting renal function change and their relationship with prognosis of RCC patients with tumor thrombus after nephrectomy and thrombectomy. The renal function change, which was associated with preoperative eGFR and pathological type, was prognostic risk factor for CSS and ACE $>13.9$ indicated the worse prognosis.

\section{Supplementary information}

Supplementary information accompanies this paper at https://doi.org/10. 1186/s12885-020-6563-7.

Additional file 1: Table S1. Patient demographic and postoperative data according to different histology

\section{Abbreviations \\ ACE: Absolute change in estimated glomerular filtration rate; CKD: Chronic kidney disease; CN: Cytoreductive nephrectomy; CSS: Cancer-specific survival; $C T$ : Computed tomography; eGFR: Estimated glomerular filtration rate; ESRD: End-stage renal disease; IVC: Inferior vena cava; MDRD: Modification of Diet in Renal Disease; MRI: Magnetic resonance imaging; OS: Overall survival; PCE: Percent change in estimated glomerular filtration rate; RCC: Renal cell carcinoma; RN: Radical nephrectomy; ROC: Receiver operating characteristic; TT: Tumor thrombus; WHO: World Health Organization}

\section{Acknowledgements}

The authors thank the entire staff of the Department of Urology, Peking University Third Hospital. And we all thank 2019 AUA Secretary and Program Committee and International Journal of Urology, because part of our manuscripts have been partly presented as conference abstracts (https:// onlinelibrary.wiley.com/doi/full/10.1111/iju.14063).

\section{Authors'contributions}

ZL, ST: Project development, Data collection, Data analysis and Manuscript writing. XT: Project development, Data analysis and Manuscript editing. HZ, GW, SZ: Project development, Manuscript editing. LM: Project development. All authors have read and approved this manuscript, and ensure that this is the case.

\section{Funding}

There were no sources of financial grants or other funding for this research. This study was not performed as part of the employment of the authors.

\section{Availability of data and materials}

All the data used to support the findings of this study are currently under embargo while the research findings are commercialized. Requests for data, 6 months after publication of this article, will be considered by the corresponding author. The e-mail address: holmes_infinity@126.com (Shiying Tang)

\section{Ethics approval and consent to participate}

The study was approved by the ethics committees of Peking University Third Hospital. Informed consent was obtained from all individual participants included in the study. The informed consent obtained was written.

Consent for publication

Not Applicable.

\section{Competing interests}

All authors declare that they have no competing interests.

Received: 4 September 2019 Accepted: 20 January 2020 Published online: 28 January 2020

\section{References}

1. Ljungberg $B$, Bensalah $K$, Canfield $S$, et al. EAU guidelines on renal cell carcinoma: 2014 update. Eur Urol. 2015;67(5):913-24.

2. Chen W, Zheng R, Zeng H, Zhang S, He J. Annual report on status of cancer in China, 2011. Chinese J Cancer Res. 2015;27(1):2-12.

3. Siegel R, Ward E, Brawley O, Jemal A. Cancer statistics, 2011: the impact of eliminating socioeconomic and racial disparities on premature cancer deaths. CA Cancer J Clin. 2011;61(4):212-36.

4. Kümmerlin IPED, Laguna MP, JJMCHdl R, PMM B. Epidemiology of renal cell carcinoma. Scand J Surg. 2004;93(2):88.

5. Bamias A, Tzannis K, Papatsoris A, et al. Prognostic significance of cytoreductive nephrectomy in patients with synchronous metastases from renal cell carcinoma treated with first-line sunitinib: a European multiinstitutional study. Clin Genitourin Cancer. 2014;12(5):373-83. 
6. Zabor EC, Furberg $\mathrm{H}$, Lee $\mathrm{B}$, et al. Long-term renal function recovery following radical nephrectomy for kidney Cancer: results from a multicenter confirmatory study. J Urol. 2018;199(4):921-6.

7. Sorbellini M, Kattan MW, Snyder ME, Hakimi AA, Sarasohn DM, Russo P. Prognostic nomogram for renal insufficiency after radical or partial nephrectomy. J Urol. 2006;176(2):472-6 discussion 476.

8. Liss MA, DeConde R, Caovan D, et al. Parenchymal volumetric assessment as a predictive tool to determine renal function benefit of nephron-sparing surgery compared with radical nephrectomy. J Endourol. 2016:30(1):114-21.

9. Campbell S, Uzzo RG, Allaf ME, et al. Renal mass and localized renal Cancer: AUA guideline. J Urol. 2017;198(3):520-9.

10. Chung JS, Son NH, Byun SS, et al. Trends in renal function after radical nephrectomy: a multicentre analysis. BJU Int. 2014;113(3):408-15.

11. Jeon $\mathrm{HG}$, Choo SH, Sung HH, et al. Small tumour size is associated with new-onset chronic kidney disease after radical nephrectomy in patients with renal cell carcinoma. Eur J Cancer. 2014;50(1):64-9.

12. Klarenbach S, Moore RB, Chapman DW, Dong J, Braam B. Adverse renal outcomes in subjects undergoing nephrectomy for renal tumors: a population-based analysis. Eur Urol. 2011;59(3):333-9.

13. Blute ML, Leibovich BC, Lohse CM, Cheville JC, Zincke H. The Mayo Clinic experience with surgical management, complications and outcome for patients with renal cell carcinoma and venous tumour thrombus. BJU Int. 2004;94(1):33-41.

14. Stevens $L A$, Schmid $C H$. Greene T, et al. comparative performance of the CKD epidemiology collaboration (CKD-EPI) and the modification of diet in renal disease (MDRD) study equations for estimating GFR levels above 60 mL/min/1.73 m2. Am J Kidney Dis. 2010;56(3):486-95.

15. Haifler M, Ristau BT, Higgins AM, et al. External validation of contact surface area as a predictor of postoperative renal function in patients undergoing partial nephrectomy. J Urol. 2018;199(3):649-54.

16. Barbeito A, Muir HA, Gan TJ, et al. Use of a modifier reduces inconsistency in the American Society of Anesthesiologists Physical Status Classification in parturients. Anesth Analg. 2006;102(4):1231-3.

17. Mandal S, Sankhwar SN, Kathpalia R, et al. Grading complications after transurethral resection of prostate using modified Clavien classification system and predicting complications using the Charlson comorbidity index. Int Urol Nephrol. 2013;45(2):347-54

18. Humphrey PA, Moch H, Cubilla AL, Ulbright TM, Reuter VE. The 2016 WHO classification of Tumours of the urinary system and male genital organs-part B: prostate and bladder Tumours. Eur Urol. 2016;70(1):10619.

19. Hongo F, Oishi M, Ueda T, et al. MP57-09 impact of targeted therapy on renal function in patients with advanced renal cell cancer. J Urol. 2014; 191(4):e645

20. Kawamura N, Yokoyama M, Fujji Y, et al. Recovery of renal function after radical nephrectomy and risk factors for postoperative severe renal impairment: a Japanese multicenter longitudinal study. Int J Urol. 2016;23(3): 219-23.

21. Clark AT, Breau RH, Morash C, Fergusson D, Doucette S, Cagiannos I. Preservation of renal function following partial or radical nephrectomy using 24-hour creatinine clearance. Eur Urol. 2008;54(1):143-9.

22. Krebs RK, Andreoni C, Ortiz V. Impact of radical and partial nephrectomy on renal function in patients with renal cancer. Urol Int. 2014;92(4):449-54

23. Yokoyama M, Fujii $Y$, limura $Y$, et al. Longitudinal change in renal function after radical nephrectomy in Japanese patients with renal cortical tumors. J Urol. 2011;185(6):2066-71.

24. Foley RN, Murray AM, Li S, et al. Chronic kidney disease and the risk for cardiovascular disease, renal replacement, and death in the United States Medicare population, 1998 to 1999. JASN. 2005;16(2):489-95.

25. Tanaka N, Fujimoto K, Tani M, Yoshii M. Prediction of postoperative renal function by preoperative serum creatinine level and three-dimensional diagnostic image reconstruction in patients with renal cell carcinoma. Urology. 2004;64(5):904-8.

26. Antoniewicz AA, Poletajew S, Borowka A, Pasierski T, Rostek M, PiktoPietkiewicz W. Renal function and adaptive changes in patients after radical or partial nephrectomy. Int Urol Nephrol. 2012;44(3):745-51.

27. Shirasaki Y, Tsushima T, Saika T, Nasu Y, Kumon H. Kidney function after nephrectomy for renal cell carcinoma. Urology. 2004;64(1):43-7 discussion 48
28. Lane BR, Novick AC, Babineau D, Fergany AF, Kaouk JH, Gill IS. Comparison of laparoscopic and open partial nephrectomy for tumor in a solitary kidney. J Urol. 2008;179(3):847-51 discussion 852.

29. Nouh MA, Kuroda N, Yamashita M, et al. Renal cell carcinoma in patients with end-stage renal disease: relationship between histological type and duration of dialysis. BJU Int. 2010;105(5):620-7.

30. Woldu SL, Weinberg AC, RoyChoudhury A, et al. Renal insufficiency is associated with an increased risk of papillary renal cell carcinoma histology. Int Urol Nephrol. 2014;46(11):2127-32.

31. Tang $Q$, Song $Y, L i X$, et al. Prognostic outcomes and risk factors for patients with renal cell carcinoma and venous tumor Thrombus after radical nephrectomy and Thrombectomy: the prognostic significance of venous tumor Thrombus level. Biomed Res Int. 2015;2015:163423.

\section{Publisher's Note}

Springer Nature remains neutral with regard to jurisdictional claims in published maps and institutional affiliations.

\section{Ready to submit your research? Choose BMC and benefit from:}

- fast, convenient online submission

- thorough peer review by experienced researchers in your field

- rapid publication on acceptance

- support for research data, including large and complex data types

- gold Open Access which fosters wider collaboration and increased citations

- maximum visibility for your research: over $100 \mathrm{M}$ website views per year

At BMC, research is always in progress.

Learn more biomedcentral.com/submissions 